\title{
Perceptions of the Nature of Happiness: Cultural, but Related to the Dynamics of the Human Mind and the Gratification of General Needs
}

\section{Laura Hyman: Happiness; Understanding Narratives and Discourses, Palgrave Macmillan, 2014, ISBN: 978-1-137-32152-7}

\author{
Jan Cornelis Ott ${ }^{1}$
}

Published online: 20 January 2016

(C) The Author(s) 2016. This article is published with open access at Springerlink.com

\begin{abstract}
In her book 'Happiness' Laura Hyman identifies some discourses, as defined by Foucault, about happiness among 19 middle-class respondents in the UK. A discourse is a way of thinking and communicating about some issue, and comparable to a 'perception' or a' view'. The dominant 'Therapeutic Discourse', is based on the view that happiness is an individual and normative challenge; it is to be worked on by selfcare and self-knowledge. A somewhat contradictory discourse puts more priority on social relations, as a condition for happiness. Hyman explains the co-existence of these discourses as a consequence of individualization. Individualization puts more priority on individual responsibility, but can easily lead to a neglect of social relations. It is difficult to assess the universality of these discourses, because the sample of respondents is very homogeneous. If individualization is an important factor we might expect different discourses in more collectivistic cultures. There are, however, theoretical reasons to believe that these discourses are rather universal. We may expect that the gratification of general needs is important. If certain needs are not gratified they will get more attention, and more priority, in a discourse about happiness. The 'Therapeutic Discourse', more in particular, is apparently a logical consequence of the dynamics of the human mind. The characteristics of the human consciousness clearly support this discourse. We need more empirical research, about discourses in different cultures, to find out for sure!
\end{abstract}

Keywords Capitalism - Discourse - Enlightenment · Gratification of needs · Happiness · Hedonic level of affect · Human needs · Individualization · Life-satisfaction

Jan Cornelis Ott

ott@ese.eur.nl

1 Erasmus University Rotterdam, Rotterdam, The Netherlands 


\section{Introduction}

Laura Hyman is Lecturer in Sociology at the University of Portsmouth, UK. She is a coconvenor of the British Sociological Association's Happiness Study Group. Her book "Happiness; Understanding Narratives and Discourses" is based on intensive interviews with 19 middle class respondents in the UK. Some questions: "What would you say makes you most happy in life"; "What do you think happiness is?"; "Would you say happiness is a short-term, fleeting feeling or a longer-lasting state?"; "Who is the happiest person you know, and why?"; "If you could be given anything to make you feel happy/happier right now, what would it be?"

Hyman uses the concept of a 'discourse', as developed by Foucault, to describe the arguments people follow if they think and communicate about specific issues. ${ }^{1}$ Hyman observes that people situate themselves within different discourses if they think and communicate about happiness. The dominant discourse is the 'Therapeutic Discourse', based on the view that happiness is an individual and normative challenge; to be worked on by self-care and self-knowledge. Such qualities are strongly advocated by the therapy industry and the self-help literature. There are alternative discourses that put more priority on external resources, like social relations, money and working life. Hyman observes that the differences and tensions between such discourses are underestimated, or even neglected, in happiness-research. I will use the less accurate but more colloquial words 'perception' or 'view' (on the nature of happiness), as substitutes for 'discourse'. 2

Hyman's book is interesting and informative about the perceptions of people of the nature and the dynamics of happiness. In her view such perceptions are no individual inventions, but elements in a specific culture, in this case elements in the individualized middle class culture of the UK. I will first summarize some key-elements in this book and then present some comments.

\section{Hyman's Book}

\subsection{The Development of the 'Therapeutic Discourse'}

Hyman observes that over the last 50 years liberal western democracies have adopted a therapeutic culture, characterized by an increased public recognition of personal pain, suffering and emotional experience. Words like 'stress', 'anxiety', 'trauma' and 'syndrome' are now used in everyday vocabulary. Life experiences such as debt, marriage, divorce and childbirth are transformed into emotion-laden 'life-events', for which 'coping' and 'adjustment' are required.

This has changed the way in which happiness is understood. It has become something to be actively striven for and reflected upon. Happiness is rendered a 'goal' that can be reached once negative feelings have been managed, 'worked through' and eradicated.

\footnotetext{
${ }^{1}$ Hyman (on page 5): "A discourse is made up of statements and is based upon a set of rules that prescribe which speech acts are to have meaning. It is these rules that are the main focus of Foucault's notion of discourse, rather than the language that is used, or the psyches of the human subjects who carry out the speech acts (Foucault 1991)".

2 The words 'perception' and 'view' are somewhat less accurate, because a 'discourse' is more specifically directed at the nature and conditions of something, and comparable to a 'lay-theory'; in this case about the nature and conditions of happiness.
} 
People are expected to be critical about their emotions and about their own identity, and have to develop a positive relation 'with themselves'. For people who adopt this perception happiness has become a major preoccupation in their consciousness.

Fostering self-knowledge and emotion-management are the general ways to achieve the required levels of happiness. Thus culture 'prescribes' socially desirable behaviour that is conducive to happiness. Factors like being in control of life, the feeling of being accepted by others, a certain degree of self-confidence and awareness of one's needs and personal aspiration are considered to be essential. In this view happiness is something to be sought and achieved by the individual, and rather independent of the environment.

There are more views on happiness in general, and there are some views on the importance of social relations, money and working life.

\subsection{More Views on Happiness in General}

Some alternative views on happiness in general:

(a) Happiness is elusive; it is an emotion experienced at the level of the nervous system which sits outside the scope of sociological inquiry; not to be defined or measured.

(b) Happiness is 'natural'; asocial, it comes from within the body and it is one's own personal responsibility.

(c) Happiness is 'biological', it can be attributed to biological or chemical processes (related to $a$ and $b$ ).

(d) Happiness is a duty; it can be achieved by positive thinking.

(e) Happiness is about unique feelings, each individual will experience happiness differently,

(f) Happiness is transient; negative and unpleasant experiences are inevitable, and one cannot, and should not, expect to be happy at all times.

These views, and in particular a, b, c and d, are consistent with the dominant 'Therapeutic Discourse' but less comprehensive.

\subsection{Views on the Importance for Happiness of Social Relations, Money and Working Life}

There are also views on the importance of specific conditions needed for happiness, in particular social relations, money and working life. Almost all the respondents believe that social relations are crucial for happiness. This view is somewhat inconsistent with the 'Therapeutic Discourse', which is based on the rather stoic assumption that happiness depends on one's own internal 'peace of mind'.

Most respondents are critical about the importance of money and consumption for happiness, even if they acknowledge that some minimum level of financial security is required. This view is consistent with the 'Therapeutic Discourse'. Funny enough all respondents believe that 'other people' put too much priority on money and consumption, and are in that sense materialistic. The respondents see themselves as being different, and believe that their non-materialism has a higher moral status. Hyman believes that this is a typical 'middle class' attitude.

Most respondents put a high priority on the quality of work for personal development and happiness. Some of them are frustrated because they are unable to find a job that offers such opportunities. This view is again somewhat inconsistent with the 'Therapeutic 
Discourse'. Hyman observes however that respondents can combine different views on happiness.

\section{Comments}

This book is somewhat long-winded; all the answers of the respondents are reported word for word ('verbatim'). This approach has, however, a substantial benefit: it gives the reader a better understanding of the different ways people think about happiness. Hyman is probably right that the perceptions of people on happiness are neglected in happiness research. It is a pity that this approach is only applied in a sample of 19 middle class respondents in the UK. This approach might have additional value, if applied in a sample of respondents with more variety in social-economic and cultural background.

I have more specific comments about three issues: (a) the distinction between hedonic level of affect and cognition as components of happiness; (b) the distinction between perceptions and actual happiness; and (c) the relation between perceptions and the gratification of universal human needs.

\subsection{The Distinction Between Hedonic Level of Affect and Cognition as Components of Happiness}

The useful and informative distinction between the two components of happiness, the hedonic level of affect and the cognitive appreciation of life, is neglected in the interviews. The hedonic level of affect, in terms of moods and emotions, is indeed rather elusive, natural and biological (views a, b and c in Sect. 2). This hedonic component is rather dominant in many views on happiness, as in Bentham's view that happiness is the balance of pleasure and pain (Bentham 1789/1988). This view is consistent with a materialistic view on human beings (La Metrie 1747).

More attention for cognition and reflection, and the autonomous power of the mind, is more consistent with an idealistic view, as in the works of Descartes, Hegel and Leibnitz. Cognition is more pervasive in the view that happiness is a duty, and in views that put a high priority on specific factors, like social relations, money and working life. Cognition is also an important factor in the therapy-industry and self-help literature (Bergsma 2008).

The 'Therapeutic Discourse' is somewhere in the middle; it values emotions but considers the working of the mind as a crucial factor. This book might have been more informative about the importance of these components, and their interaction, ${ }^{3}$ if the respondents would have been invited to use this distinction in their reports.

\subsection{Perceptions and Actual Happiness, Mind the Difference}

This book is not about actual measured happiness but about perceptions of, or views on, the nature of happiness. ${ }^{4}$ We know from previous research that such perceptions can be biased;

\footnotetext{
3 These two components of happiness can also be treated as different types of happiness: affect or hedonic level of affect, and life-satisfaction, or contentment. The intensive and continuous interaction between affect and cognition leads to 'overall happiness' as defined by Veenhoven (1984).

4 The measurement of actual happiness is independent of perceptions of its causes. Following Veenhoven (1984) we may define happiness as 'the degree to which an individual judges the overall quality of his or her life-as-a-whole favourably'; in other words 'how much one likes the life one lives'. Since happiness is
} 
people can make substantial mistakes about the nature of happiness (Gilbert 2007). The level of average happiness in nations can be explained quite well without referring to subjective variables like perceptions. Subjective variables can play a more prominent role in explaining individual differences within nations. ${ }^{5}$ It is possible that there are relations between perceptions and actual levels of happiness, but it requires serious empirical analysis to establish such relations. ${ }^{6}$

Perhaps Hyman is somewhat careless at this point, where she tries to explain how people can combine the self-oriented 'Therapeutic Discourse', with the perception that social relations are crucial. In her view capitalism leads to individualization, with negative feelings of powerlessness and loneliness. This makes the 'Therapeutic Discourse' attractive as a means of feeling more guided by ideas provided by the therapy industry and the self-help literature. However, this individualization leads simultaneously to a strong desire and need for social relations. This is a well-known issue in the history of sociology and happiness research, starting with Tönnies (1887) and Durkheim (1893). ${ }^{7}$

This explanation of Hyman is incomplete in two ways. Individualization can lead to negative feelings and lower levels of happiness, ${ }^{8}$ but it is not self-evident that this will change the perceptions on happiness as suggested. People may also try to redress individualization by some intensification of social relations, e.g., in their family, in religious organizations, political parties, and trade-unions. Hyman's explanation is also incomplete since individualization started in most nations in the $19^{\text {th }}$ century, with the advent of capitalism, while the 'Therapeutic Discourse' was adopted over the last 50 years.

Perhaps it is more realistic to speculate that perceptions on happiness changed, as suggested, by different developments.

(a) People became more inclined to decide about their own values and priorities by the Enlightenment, and by getting familiar with different cultures. The last 50 years this development is reinforced by immigration and globalization.

(b) The advent of capitalism in the $19^{\text {th }}$ century has led (indeed) to individualisation and alienation.

(c) As a finishing touch, the substantial economic growth over the last 50 years created more opportunities to pay attention to social and psychological problems. The therapy industry and the self-help literature have become 'big business'.

Footnote 4 continued

something individuals have in mind it can be measured using questions. Many different questions are used; for an overview see the collection of Happiness Measures that is part of the World Database of Happiness (Veenhoven 2014). People think frequently about their happiness, and are quite well able to answer such questions. Their answers are in general reliable and comparable, but the reliability of the results is better at aggregate levels.

5 In general only about $5 \%$ of the differences in individual happiness within rich nations can be explained with objective variables like employment, marital status, age and income. Introducing subjective variables, like optimism or trust, makes a substantial difference and may lead to the explanation of $40 \%$ of the differences.

6 The difference between actual happiness and perceptions is comparable to the difference between actual happiness and preferences or (explicit) wants. In the economic terminology: actual happiness is about experienced utility; preferences, perceptions, and wants are about expected utility. It is the task of happiness researchers to pay attention to the differences between experienced and expected utility. Perceptions, preferences and wants are the objects of heavy manipulation by many fellow-citizens, like our best friends, partners, family, politicians and advertisers!

7 Three more recent publications about this issue: Lane (2000), Layard (2005) and Putnam (2000).

${ }^{8}$ However, the impact of individualization on happiness is probably positive on the balance; see Veenhoven (1999). 


\subsection{Perceptions on Happiness and the Gratification of Universal Human Needs}

The perceptions of happiness in this book are elements in the individualized middle class culture of the UK. But since we cannot compare these perceptions with the perceptions in different (sub-) cultures we do not know how unique or universal these perceptions really are. The developments just mentioned are no longer unique for western-market democracies, but are visible in many countries.

To get some idea of the universality we can assess the connection between such perceptions and general human needs. The Dutch social scientist Wentholt developed a typology of motivations, referring to general human needs. ${ }^{9}$

(A) Motivations based on homeostatic regulation:

(a) Internal physiological regulation (the need to maintain body-temperature),

(b) Hunger, thirst,

(c) Sexuality,

(d) The emergency motivations: aggression and fear (need for safety).

(B) Motivations based on stimuli-seeking:

(a) Intrinsic motivation, directed at the development of capabilities (need for appropriate challenges),

(b) Affection.

These needs are not typical human, but some characteristics of the human consciousness have a substantial impact on the relative importance and dynamics of these needs. Wentholt discerns the following characteristics of the human consciousness:

(a) Awareness of cognitive inconsistencies,

(b) Awareness of moods and emotions,

(c) Awareness of existential conditions,

(d) Awareness of one's own identity.

These characteristics are very important for the perception of happiness. The fact that people recognize inconsistencies will stimulate them to develop a consistent perception of happiness in general, and their own happiness in particular. Their awareness of their moods and emotions, existential conditions and identity is important in the development of these perceptions. It is therefore not a big step for people to adopt a 'Therapeutic Discourse', based on the view that happiness is an individual and normative challenge; to be worked on by self-care and self-knowledge. This adoption is a small and logical step, as soon as happiness is accepted as a goal.

It is also important to observe that the gratification of needs is important for the perceptions. If specific needs, e.g., for safety, sexuality, affection and appropriate challenges, are frustrated, then they will get a higher priority in the perceptions. The priority of needs in the perception depends on the gratification, and this creates a relation between the perception and the environment in terms of culture and livability.

\footnotetext{
9 This typology of Wentholt (1980) is in some respects comparable with Maslow's typology, but without any assumptions about a hierarchy of needs, and with more attention for the characteristics of the human consciousness.
} 
The combination of the 'Therapeutic Discourse' with a high priority for social relations in affluent western nations is therefore understandable. Social relations are somewhat neglected in these nations and are important for the gratification of different needs, in particular the need of affection. It is also understandable that work is important as a source of appropriate challenges to develop capabilities.

\section{Conclusion}

We may conclude that the 'Therapeutic Discourse' is probably very common in many nations with different cultures, but with different priorities for specific needs. Such differences in priorities can be a consequence of differences in the gratification of general needs. This conclusion is consistent with happiness-research (Veenhoven 2010). What we really need, however, is empirical research to find out for sure. Hyman's approach deserves a multicultural follow-up.

Open Access This article is distributed under the terms of the Creative Commons Attribution 4.0 International License (http://creativecommons.org/licenses/by/4.0/), which permits unrestricted use, distribution, and reproduction in any medium, provided you give appropriate credit to the original author(s) and the source, provide a link to the Creative Commons license, and indicate if changes were made.

\section{References}

Bentham, J. (1789/1988). The principles of morals and legislation. New York: Prometheus Books.

Bergsma, A. (2008). The advice of the wise: Introduction to the special issue on advice for a happy life. Journal of Happiness Studies, 9(3), 331-340.

Durkheim, E. (1893). The division of labour in society.

Foucault, M. (1991). Politics and the study of discourse. In G. Burchell, C. Gordon, \& P. Miller (Eds.), The foucault effect: Studies in governmentality: With two lectures by and an interview with michel foucault (pp. 53-72). Chicago: University of Chicago Press.

Gilbert, D. (2007). Stumbling on happiness. New York: Vintage books, Random House.

La Metrie, J. O. (1747). L'Homme machine.

Lane, R. (2000). The loss of happiness in market-democracies. London: Yale University Press.

Layard, R. (2005). Happiness: Lessons from a new science. London: The Penguin Press.

Putnam, R. (2000). Bowling alone: The collapse and revival of American Community. New York: Simon \& Schuster.

Tönnies, F. (1887). Gemeinschaft und Gesellschaft.

Veenhoven, R. (1984). Conditions of happiness. Dordrecht: Kluwer Academic Publishers.

Veenhoven, R. (1999). Quality-of-life in individualistic society: A comparison of 43 nations in the early 1990's. Social Indicators Research, 48, 157-186.

Veenhoven, R. (2010). How universal is happiness? In E. Diener, J. F. Helliwell \& D. Kahneman (Eds.), International differences in well-being (Chapter 11, pp. 328-350). Oxford: Oxford University Press.

Veenhoven, R. (2014). Measures of happiness. In World database of happiness. Rotterdam: Erasmus University Rotterdam.

Wentholt, R. (1980). Motivation-theory. Unpublished reader, Erasmus University Rotterdam. 